\title{
Promoting Students' Mental Health: A Study of Inter-professional Team Collaboration Functioning in Norwegian Schools
}

\author{
Elin Borg ${ }^{1}\left[\varnothing^{\circ}\right.$ Øyvind Pålshaugen ${ }^{1}$
}

Published online: 22 September 2018

(c) The Author(s) 2018

\begin{abstract}
Collaboration between different professions is thought to be important for mental health work in schools. However, highquality collaboration is often difficult to achieve in practice, and there is little research available to inform strategies for strengthening collaboration. This study analyzes the effects of the research and development project School as an arena for child and adolescent mental health, aimed at developing practices for promoting students' mental health in Norway. We collected questionnaire data from all professions participating in collaboration teams in the four participating municipalities $(n=40)$ and 27 comparison municipalities $(n=197)$. The main findings indicate that the project initiative positively affected innovation practices in collaboration. We discuss the results in light of the design of the project and field data collected over a 4-year period.
\end{abstract}

Keywords Collaboration $\cdot$ Inter-professional $\cdot$ School $\cdot$ Education $\cdot$ Mental health $\cdot$ Prevention

\section{Introduction}

Educational achievement and school completion are interrelated components of the healthy development of young children and youth, and schools are facing increasing pressure to improve academic outcomes for young people. Nonacademic barriers to learning, such as emotional, behavioral, and health problems, often create significant difficulties in helping young people succeed at school, and teachers in classrooms are struggling to balance individual needs and teaching the whole class (Anderson-Butcher et al., 2008; Maynard, Kjellstrand, \& Thompson, 2013).

The Norwegian parliament and international organizations have highlighted the association between mental health and learning by developing and evaluating initiatives for improved school environments, including mental health interventions, prevention work, and the early identification of students in need of special attention in school (White Paper No. 21, 2016-2017; WHO, 2004). Combining

Elin Borg

elin.borg@oslomet.no

Øyvind Pålshaugen

op@oslomet.no

1 Work Research Institute, Oslo Metropolitan University, P.O. Box 4, St. Olavs Plass, 0130 Oslo, Norway psychosocial and academic perspectives in school are thought to positively affect students' well-being, learning environments, and learning outcomes, while reducing dropout rates (Banks, Squires, \& Anhalt, 2014; Holen \& Waagene, 2014). As a result, combining these perspectives may in the long run reduce mental health issues and unemployment. Research indicates that collaboration across professions-such as between teachers, nurses, and social workers-is a necessary and viable tool in an educational world where complexity increases (Weist et al., 2012; Winitzky, Sheridan, Crow, Welch, \& Kennedy, 1995).

A collaborative work environment has become the norm for many types of organizations (Decuyper, Dochy, \& Van den Bossche, 2010; Vangrieken, Dochy, Raes, \& Kyndt, 2015), and several factors can explain why collaboration between disciplines is of importance in schools. First, a collaboration between disciplines acknowledges that teachers are facing an increasingly complex student population with differentiated needs. Second, collaboration acknowledges that schools are social systems where students spend most of their days. The role of the school in creating a good psychosocial school environment is therefore important. Third, teachers are bound by limited training, time, and resources, which make it difficult to tend to challenges with mental health promotion alone (Ekornes, 2015; Hornby \& Atkinson, 2003). Different professionals within schools and in the 
wider school environment serve diverse aspects of students' needs, which may lead to compartmentalization of students' problems, rather than contributing to a unified school experience (Hart, 1998). More integrated services are required for both welfare and educational professions in order to fulfill their specific mandates and to provide children with a holistic and coordinated service securing good learning and formative conditions (Galvin \& Erdal, 2013; Mellin, 2009; Welch et al., 1992; Willumsen \& Ødegård, 2016; Ødegård, 2005).

Even though educational policies promote interdisciplinary collaboration in schools, there are ongoing discussions on how such interdisciplinary collaboration should be organized to best accommodate the needs of teachers and students (Borg, Drange, Fossestøl, \& Jarning, 2014; Holen \& Waagene, 2014; Shoffner \& Briggs, 2001; Weist et al., 2012). A number of studies have investigated specific interventions and factors assumed to promote high-quality collaboration (e.g., Connolly \& James, 2006; Gajda \& Koliba, 2007; Meirink, Imants, Meijer, \& Verloop, 2010; Mellin, Anderson-Butcher, \& Bronstein, 2011; Shoffner \& Briggs, 2001; Weist et al., 2012). However, studies evaluating interventions that target interdisciplinary collaboration to promote students' mental health are scarce.

The research and developmental project, "School as an arena for child and adolescent mental health" (SAMH), was designed to gain insight into how schools can promote mental well-being among students in Norway. One important aspect in the project was promoting collaboration between educational professions and health professions in schools. Four years into the project, we conducted a survey among professionals collaborating in teams to evaluate the quality of collaboration. This survey was designed to examine whether and in which ways the SAMH project has had an impact on the quality of interdisciplinary collaboration in teams. The survey therefore comprised professionals participating in the project and a larger comparison group in a random sample of municipalities. The comparison group comprised a number of schools large enough to also serve as a mapping of the quality of interdisciplinary collaboration in the compulsory school sector.

Norway is an interesting case for studying differences in collaboration practices because the nation has come a long way in integrating social and academic aspects into educational policy. There are small social differences between schools and municipalities, few students attend private school, and a national curriculum provides students with similar education. However, there are no national guidelines for collaborative practices between education and health professionals, thus making municipalities and schools free to develop their own practices. This education policy may allow local initiatives to improve collaboration between disciplines in accordance with local needs. However, it may also serve to maintain the status quo. Therefore, we aimed to conduct a survey that would provide an overview over the quality of collaboration between disciplines in Norwegian compulsory schools compared to the SAMH project schools. Given that we also conducted interviews and observations during the implementation process, we have suitable data at both macro and micro levels to address our two main research questions: (1) How is collaboration between disciplines for promoting children and youth mental health organized in Norway? And (2) to what degree and in which ways has the SAMH project had an impact on the quality of such collaboration?

\section{Theories of and Research on Interdisciplinary Collaboration Practices}

Collaboration is widely recognized as a means for change (Austin, 2000; Gajda \& Koliba, 2007), and an important background for SAMH was that teachers and other professionals reported poor collaboration between teachers and other professions in school (Ekornes, Hauge, \& Lund, 2012; Eriksen \& Lyng, 2015; Holen \& Waagene, 2014). Teachers report lack of knowledge about psychosocial and mental health issues, too few arenas for collaboration between disciplines, and unproductive meetings with unclear goals and expectations in arenas where different professionals actually meet (Pounder, 1998). There is, as such, a call for relevant welfare services to support both schools and teachers in their systemic challenges and preventive work (Hustad, Strøm, \& Strømsvik, 2013; White Paper No. 19, 2009-2010).

Collaboration can roughly be defined by people working together to achieve mutually desired outcomes (Gajda \& Koliba, 2007). However, collaboration practices are varied and complex processes. In the framework by Choi and Pak (2006, 2007), collaborative practices are regarded as a continuum ranging from multidisciplinary, where disciplines work separately within their boundaries, to transdisciplinary, where disciplines develop integrated knowledge across professional boundaries. In between these two endpoints lies interdisciplinary collaboration, defined by a practice of discussing and sharing information and experiences across disciplines and finding alternate ways of handling common problems. Interdisciplinary collaboration is often put forward in research as a more appropriate way to collaborate in schools compared to multidisciplinary approaches (Meirink et al., 2010; Mellin et al., 2011; Shoffner \& Briggs, 2001; Weist et al., 2012).

Hammerness et al. (2005) also distinguishes between different dimensions of collaboration, such as efficiency, where the goal of collaboration is more efficiency with a minimal amount of resources, and innovation, characterized by improvement and development, where collaborators give up 
old routines and change prior beliefs. Innovation or newly established professional practices require that collaborators combine their expertise to create innovative solutions and support in working with children and youths (Bronstein \& Abramson, 2003; Meirink et al., 2010; Mellin et al., 2011). It is this latter form of collaboration that is argued to be highquality collaboration. However, the most appropriate form of collaboration may vary with the defined challenge. In some cases, it may be more effective to work in a multidisciplinary fashion, whereas more complex cases may require integrated collaboration efforts. A good collaboration climate is, however, essential for effective group collaboration regardless of the defined challenge.

In many instances, working separately (multidisciplinary) with the same students and challenges can be unproductive for students, teachers, and welfare services. However, collaboration between disciplines can be complicated due to differences in education, differences in professional traditions, and differences in approaches to dealing with the challenges members of teams are facing (Shoffner \& Briggs, 2001). Most teachers recognize that mental health promotion is part of their professional responsibilities. However, lack of time and mental health knowledge, in combination with other services, and lack of understanding of the school context makes collaboration difficult.

Getting familiar with other professions' roles and mandates in the collaborating team may help to overcome some of these challenges. Lack of knowledge about one another can lead to conflicts, territoriality, and ineffective use of time and energy (Connolly \& James, 2006; Shoffner \& Briggs, 2001; Weist et al., 2012). High-quality collaborating with other disciplines can increase the team members professional knowledge and skills, provide professional support, reduce service duplication, increase access to services for students and families, and broaden the range of prevention and intervention services in schools (Andersson-Butcher \& Ashton, 2004; Mellin et al., 2011).

The literature on successful interdisciplinary collaboration has identified several factors contributing to successful collaboration, such as knowledge of other professions, interdependence $^{1}$ (Bronstein, 2003; Mellin et al., 2010, 2011), reflection on process (Bronstein, 2003; Mellin et al., 2010, 2011; Gajda and Koliba, 2007), and professional flexibility (Meirink et al., 2010; Porter, Epp, \& Bryan, 2000). Being explicit about roles and responsibilities can lead to team members being more open and flexible in their own contribution to the team or in activities initiated by the teams (Mattessich \& Monsey, 1992; Weist et al., 2012). A measure of high-quality collaboration can be how much professionals

\footnotetext{
$\overline{1}$ The degree to which collaborators rely on interaction with other professions to achieve goals and activities.
}

are willing to expand traditional roles and behaviors that support flexibility in professional thinking and roles such as mutual respect, communication, and compromise (Bronstein \& Abramson, 2003; Mattessich \& Monsey, 1992; Mellin, 2009; Mellin et al., 2011). In SAMH, school staff and collaboration partners were engaged in discussions on challenges impeding mental health work in schools, and on how to overcome such challenges. In such processes, professions get to know one another better than in other systems and, as such, would be more confident in each other's roles and mandates. We anticipated therefore professionals participating in SAMH to obtain better knowledge of each other's roles and mandates compared to the comparison group.

Mutual respect, trusting one another, and being able to compromise are other important factors for collaboration to succeed (Mattessich \& Monsey, 1992; Meirink et al., 2010). Johnson, Pas, Loh, Debnam, and Bradshaw (2017) showed how teachers' openness to implementing new initiatives can be affected by a range of factors, and often reflect the organization in which they work. Research also shows that collaboration groups where all members decide conjointly how the group works and who is part of the decision making are more likely to be successful than more hierarchically organized groups (Connolly \& James, 2006; Mebane \& Galassi, 2003). It is therefore important to conceptualize developmental work as a process in which attitudes can change. In the development work in SAMH schools, we addressed obstacles for collaboration between disciplines. Promoting collaboration was at the core of the project, and therefore, we expected SAMH participants to be more likely to have more positive relations and joint say in collaboration settings compared to other systems.

Team collaboration that leads to innovative practices is often engaged in an ongoing process of frequent, continuous, and concrete discussions about practice (Little, 1987). In the school improvement literature, essential components of collaboration include dialogue, decision making, action, and evaluation. Such a dynamic cycle leads team members to address problems as they arise, to find high-quality solutions, and to implement sustainable changes (Gajda \& Koliba, 2007; Schmoker, 2005). In this paper, we call this dynamic cycle reflection on process, which is characterized by how collaborators both evaluate their work together and how they incorporate feedback (Bronstein, 2003; Mellin et al., 2010, 2011). We expect that SAMH participants are more frequently involved in innovative practices than other participants. 


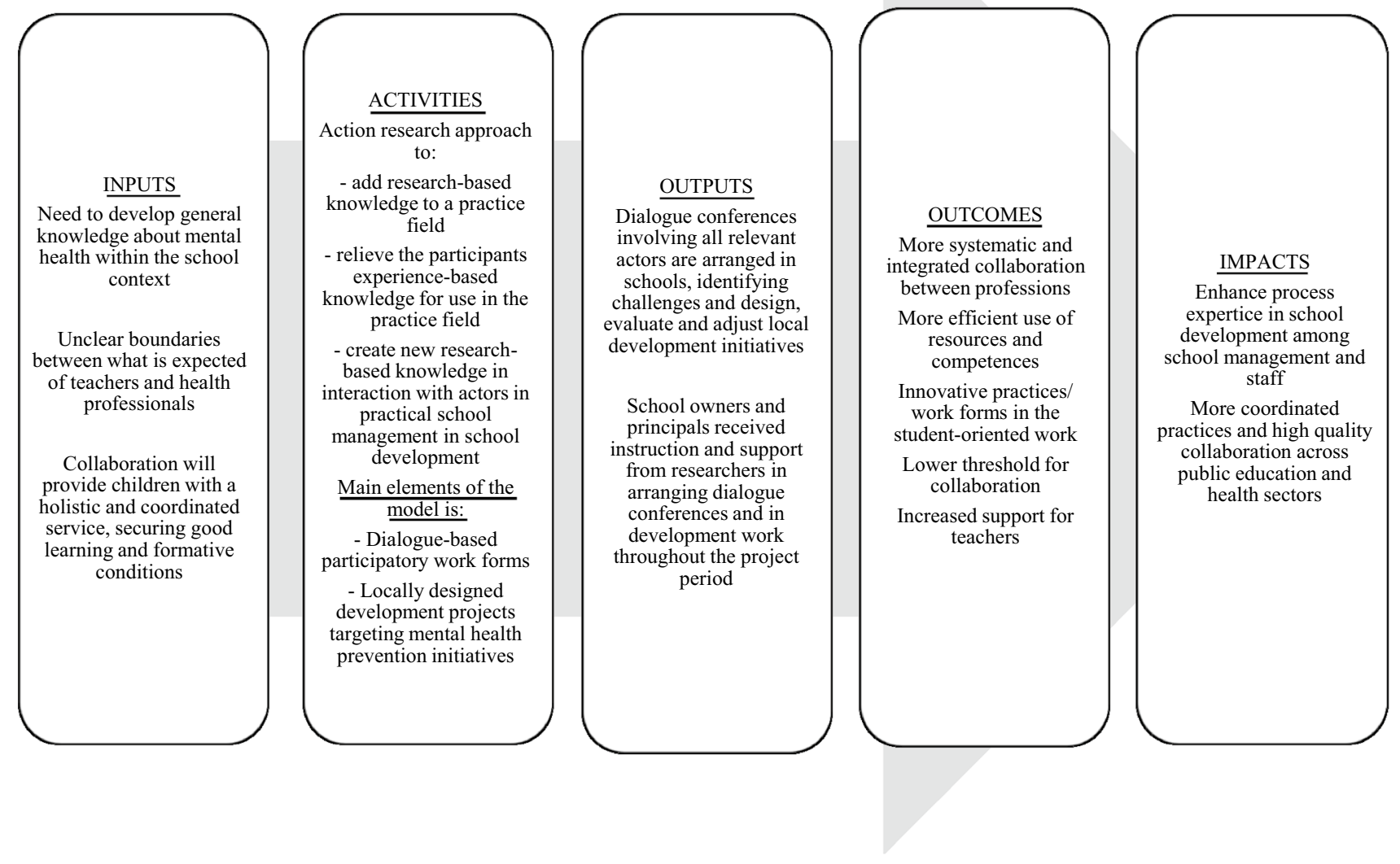

Fig. 1 A logic model for SAMH. Note Inspired by Funnel and Rogers' pipeline logic model (Funnell \& Rogers, 2011, p. 244)

\section{School as an Arena for Child and Adolescent Mental Health}

The present research is conducted in Norway. Norway and other Scandinavian countries are considered to show relatively low prevalence of childhood and adolescent mental disorders, compared to other Western countries, including the US (Wichstrøm et al., 2012). Still, it has been estimated that $15-20 \%$ of Norwegian children and adolescents experience reduced function due to symptoms of mental disorders such as anxiety, depression, and behavior disorders (Suren et al., 2016). Of these, approximately half (8\%) are estimated to suffer from severe symptoms that meet the requirements for a psychiatric diagnosis (Suren et al., 2016). Moreover, about $5 \%$ of all Norwegian children and adolescents receive each year treatment from specialized mental health care services (Suren et al., 2018).

SAMH was designed as a research and development (R\&D) project in which schools were invited to find answers to how they could develop better practices in promoting students' mental health. The objective of SAMH was to gain insight into how good practice in schools and municipal services work to promote child and adolescent mental health (Løken, 2017). The project was initiated and financed by the Directorate for Education and Training in collaboration with the Directorate of Health.

In a Norwegian school context, the term mental health is often associated with questions about mental health problems or mental disorders. Thus, working with mental health at school has traditionally had a primary focus on students who "struggle" and those with mental difficulties in need of special attention in teaching (Uthus, 2017; Bru, Idsøe, Cosmovici, \& Øverland, 2016). Consequently, work on mental health in school is often rather characterized by ad hoc work than prevention. Similarly, mental health work is often left to the social and health staff at schools. Although there is a broad consensus that schools are an arena for mental health promotion, it is less obvious how this work should be done.

The development work in SAMH did not consist of introducing a fully developed program or methods to promote students' mental well-being (see Fig. 1). Instead, the municipalities and schools received a combination of economic and 
research support to do development work to improve their practice in this field.

Throughout the project period, school management and representatives from the participating schools participated in one dialogue conference a year, resulting in a total of four dialogue conferences during the 4 year span of the project. The conferences were common arenas for dialogue and evaluation of initiated activities and mapping the way forward. Based on these dialogues, a number of schools also arranged dialogue conferences for the whole staff with similar purposes.

The project was aimed at stimulating school owners and principals to take an active part in the developmental work together with school staff and collaborating partners. Moreover, the project stressed the importance of decision-making processes in which all educational and mental health professionals participated in developing new and better practices in student-oriented work. Such dialogue-based development work allows participants from all professions to discuss challenges and how to overcome them on an equal footing. Schools could, as such, find different ways to reach their goals of improving mental health promotion practices in line with local conditions. The background for this bottom-up approach was the acknowledgment that needs and contexts differed among the participating schools and municipalities. Schools and municipalities had to consider this variation when developing practices. This approach was also applied to ensure that the outcome of the project would sustain beyond the project period.

The goal for the dialogue conferences was that the dialogue was kept to processes, and therefore, the activities were kept lively. This process ensured that teachers and school leaders continued with the development work over a long period, making the process more likely to result in improved practices that become an integral part of the daily work (Blossing, Nyen, Söderström, \& Tønder, 2012).

As Fig. 1 shows, researchers supported school management in their development work in schools by being a "critical friend" and discussion partner throughout the project period. Researchers also contributed in organizing the dialogue conferences at the local schools, in which school staff and collaborating partners discussed how to work better to promote students' mental health.

\section{Method}

The approach in the SAMH project was an $R \& D$ project based on and performed by a triangulation of methods. We used action research methods to support the actors in the field in their development work (Gustavsen, 1992; Pålshaugen, 2014) and observations and interviews in field studies. Moreover, we used a survey targeting both the schools included in the SAMH project and a larger comparison group. The results from the quantitative analyses form the main basis for this article; however, to elaborate on the interpretation of the results, we complemented with qualitative empirical material collected during the project. The qualitative data consisted of observation and field notes from dialogue conferences and observations in eight different collaboration teams followed by group interviews. Moreover, interviews with six project leaders (whereas four were principals), 14 elementary schools teachers, and eight junior high schools teachers were conducted. All interviews were transcribed, and interviews and field notes were analyzed by using the qualitative data analysis software package NVivo.

\section{Survey Participants}

Four municipalities were recruited to take part in an $R \& D$ project to promote children and youths' mental health in school. The municipalities were informed that the project aimed at facilitating collaboration between educational staff and other profession within health/social disciplines working in schools (such as school nurses and social workers) and outside schools (such as educational and psychological counselors and staff working in child welfare services).

A questionnaire was sent electronically to participants of all collaboration teams in fall 2017 at the end of the project when the SAMH had been implemented for 4 years. We also recruited municipalities not part of SAMH as a comparison group. More specifically, we randomly selected 40 of 163 municipalities that participated in 2017 in a large youth survey ("Ungdata 2017"). ${ }^{2}$ Thirty-two municipalities $(80 \%)$ agreed to be part of the study. The participating municipalities provided us with e-mails to professionals participating in collaboration teams. Of 788 e-mails sent, we received 481 responses (SAMH participants: $n=40$, comparison group: $n=441$ ), resulting in a response rate of $61 \%$. To ensure that the two samples were as equal as possible, we matched the comparison municipalities with the SAMH municipalities on size and economic conditions in the municipalities according to national statistical measures (KOSTRA) collected and made available by Statistics Norway. Based on KOSTRA information, we excluded data from five municipalities which either were considerably larger in size (four municipalities) or showed to score higher on economic indicators (one municipality) than the

\footnotetext{
${ }^{2}$ Ungdata is a questionnaire survey conducted among students in junior and senior high schools to map central aspects of students' lives in Norway. The survey is not related to any form for intervention or program that may have influenced collaboration practices. The survey is funded by the Norwegian government and all municipalities in Norway take part in the study in different cycles.
} 
SAMH municipalities. As a result, data from the four SAMH municipalities and 27 comparison municipalities were used, with 40 and 197 collaboration team members from SAMH and comparison municipalities, respectively. When comparing the two groups on background variables such as gender, age, and living conditions, we found no differences between members in the two groups $(p>.05)$. Moreover, as differences between schools in Norway are considered to be rather small, we concluded that there is no reason to believe that the two samples differed in collaboration practices before the implementation of SAMH.

\section{Measures}

\section{Meeting Frequency}

Meeting frequency was measured through a question on how often the collaboration team met. Responses were once a year (1), once a semester (2), multiple times in one semester (3), once a month (4), multiple times a month (5), and once a week (6).

\section{Need for Inter-professional Teamwork}

We asked the respondents to what extent they experienced a need for collaboration between different disciplines. Responses were given on a 5-point Likert-type scale, ranging from 1 (not at all) to 5 (very much so).

\section{Knowledge of Other Professional Mandates}

Knowledge of other professions' mandates refers to how well the collaborators knew other service mandates, competences, and procedures for follow-up with children and youths. The collaborators were asked to rate how well they knew the mandate and competence of: (1) school, (2) school health services, (3) educational and psychological counseling services, and (4) child welfare authorities. Moreover, we assessed how well the collaborators knew: (1) procedures for confidentiality and use of consent, (2) procedures for reporting to child welfare services, and (3) procedures for collaboration across services. Responses were given on a 5-point Likerttype scale, ranging from 1 (not at all) to 5 (very well). Mean scores were computed for the seven items, with higher scores indicating greater knowledge of other services' mandates and procedures for collaboration. Measures of internal consistency indicated acceptable reliability $(\alpha=.80)$.

\section{Openness and Experienced Support}

Collaborators' openness and experienced support were measured by seven items translated and adapted from the
Index of Interprofessional Team Collaboration-Expanded School Mental Health (IITC-ESMH) (Mellin et al., 2011). The respondents were asked to rate the following statements on a 5-point Likert-type scale (from 1-strongly disagree to 5-strongly agree): (1) team members respect of one another even when they have different ideas about how to help youth, (2) the team welcomes new ideas about how to help youth, (3) team members focus on understanding the perspectives of others rather than defending their own specific opinions, (4) the team respects the opinion and input of each member, (5) the team supports each member in his or her work with youths, (6) the team works together to resolve problems, and (7) there is room for disagreement on the team. Mean scores were computed with higher scores indicating more openness and experienced support. Measures of internal consistency indicated excellent reliability $(\alpha=.92)$.

\section{Reflection on Process}

Team members' reflection on process was measured by responses to four items adapted from the IITC-ESMH (Mellin et al., 2011). Items included: (1) team members discuss strategies to improve their working relationship, (2) the team incorporates feedback about its process to strengthen its effectiveness, (3) the team informally and/or formally evaluates how they work together, and (4) the team informally and/or formally evaluates how they work together to strengthen its effectiveness. Responses were given on a 5-point Likert-type scale, ranging from 1 (strongly disagree) to 5 (strongly agree). Mean scores were computed, with high scores representing high reflection on process. Internal consistency was good $(\alpha=.86)$.

\section{Reflection on Roles}

Reflection on roles was measured by five items adapted from the IITC-ESMH (Mellin et al., 2011). Collaborators were asked to rate the following statements on a 5-point Likert-type scale (from 1-strongly disagree to 5-strongly agree): (1) team members talk about similarities and differences among their professional roles in working with youths, (2) the team discusses the degree to which each professional should be involved with a particular youth, (3) the team discusses who should be involved with students/ groups of students, (4) the team discusses the different team members' responsibilities in the cases we discuss, and (5) the team works toward the same goals. Internal consistency was acceptable $(\alpha=.79)$.

\section{Newly Created Professional Activities}

Newly created professional activities were measured by four items adapted from the IITC-ESMH (Mellin et al., 2011). 
The items included: (1) team members take on tasks outside their role when necessary, (2) as a result of working as a team, support for youth is delivered in new ways, (3) new practices related to working with youth occur as a result of the diversity of ideas among team members, and (4) the roles and/or responsibilities of team members change as a result of teamwork. The respondents were asked to rate the statements on a 5-point Likert-type scale (from 1-strongly disagree to 5-strongly agree). Mean scores were computed where higher scores indicated a higher degree of newly created professional activities. Measures of internal consistency indicated acceptable reliability $(\alpha=.80)$.

\section{Results}

\section{Descriptive Analyses}

Because municipalities and schools in Norway are relatively free to manage and develop collaboration across disciplines themselves, we expected that schools and municipalities organize collaborative practices in various ways. The sample consisted of a range of different professions working in a range of different services. After categorizing the sample into four overall categories, we found that $46 \%$ of the sample worked in school as leaders or pedagogical staff, $26 \%$ had a health background (such as school nurse [19\%] or general practitioner), $13 \%$ worked in educational and psychological counseling, and $8 \%$ worked in child welfare services. Six percent did not report their work affiliation. A majority of the sample was women $(87 \%)$, and the mean age was 28 years, ranging from 24 to 67 years.

Eighty-six percent of our respondents reported that they collaborated in teams with other professions. Team collaboration was organized in one of two ways. Some municipalities had collaboration teams targeting children and youth organized by the municipality ( $n=136,67 \%)$, whereas other municipalities organized collaboration between different disciplines within the school context $(n=68,33 \%)$. There are reasons to believe that school-based teams have a different makeup of participants compared to teams at the municipality level. We asked who participated in teams organized by school compared to municipalities. The main four participants in teams organized by both schools and municipalities were school nurses, principals, representatives from educational and psychological counseling services, and representatives from child welfare services. We conducted an independent-samples $t$ test to compare the scores on quality of collaboration practices for teams organized by schools compared to teams organized by municipalities. We did not find any significant differences in collaboration team functioning between collaborations teams organized by schools or by the municipality $(p>.05)$.

\section{Comparing SAMH Municipalities and the Comparison Group}

To study whether SAMH municipalities differed from the comparison group in collaboration practices, we first conducted correlation analyses separately for the SAMH municipalities and the comparison group. Table 1 presents the correlations for all variables used in the study for the SAMH group (above diagonal) and the comparison group (below diagonal). The table shows a higher correlation between meeting frequency and newly created professional activities in the SAMH group than in the comparison group. Both samples showed positive correlations between an open and supportive meeting arena, reflection on roles, and newly created professional activities. However, the correlations were higher in the SAMH group. In the comparison group we found a significant relationship between an open and supportive meeting arena and reflection on process.

Correlation analyses further showed that knowledge of other professions was positively correlated with openness and support in teams for the comparison group only. Good knowledge about others, thus, had a positive relationship with whether the team members respect and support one another in team collaboration. Knowledge of other professions did not correlate with whether the team reflects on process or not, whether they reflect on roles, or whether they innovate in their practice. In the comparison group we found that team members that met more often also reported more knowledge of other professions.

Looking at the means in the two samples (see Table 1), the SAMH group $(M=2.97, \mathrm{SD}=.82)$ reported fewer meeting points than the comparison group $(M=3.45, \mathrm{SD}=.99$; $t[202]=2.51, p=.01)$. The two samples also reported profound knowledge of other professions' mandates (SAMH group: $M=4.28, \mathrm{SD}=.47$; comparison group: $M=4.25$, $\mathrm{SD}=.47 ; t[235]=.38, p=.71)$, and a clear positive attitude to the need for teamwork with different disciplines (SAMH group: $M=4.28, \mathrm{SD}=.85$; comparison group: $M=4.31$, $\mathrm{SD}=.79 ; t[232]=.25, p=.81)$. Ninety-one percent of the sample responded that there was a large or a very large need for collaboration teams across disciplines.

As for the quality of collaboration practices, we found the highest scores related to experiencing openness and support in team collaboration (SAMH group: $M=4.14$, comparison group: $M=4.02$ ) and the lowest scores on reflection on process (SAMH group: $M=3.16$; comparison group: $M=3.03$ ). An independent-samples $t$ test was conducted to compare the scores on the quality of collaboration practices for the SAMH sample compared to the comparison group. We found significant differences in reflection on roles scores between the SAMH group $(M=3.81, \mathrm{SD}=.44)$ and the comparison group $(M=3.54, \mathrm{SD}=.66 ; t[51.74]=2.82, p<.01)$. We also found significant differences between the groups 
on reported newly created professional activities (SAMH group: $M=3.41, \mathrm{SD}=.57$ and comparison group: $M=3.17$, $\mathrm{SD}=.61 ; t[197]=1.97, p=.05)$. The magnitude of the differences in the means was medium for both reflection on roles (Cohen's $d=.48$ ) and innovation (Cohen's $d=.41$ ).

We found no significant differences in scores between the two groups on experienced openness and support in the team (SAMH group: $M=4.14, \mathrm{SD}=.50$; comparison group: $M=4.02, \mathrm{SD}=.56 ; t[202]=1.09, p=.28)$ or on reflection practices in teams (SAMH group: $M=3.16, \mathrm{SD}=.81$; comparison group: $M=3.03, \mathrm{SD}=.77 ; t[196]=.80, p=.43$ ).

\section{Innovation in Collaboration Teams}

Until now, we have investigated the strength and relationship between the variables. To investigate whether the SAMH intervention had an impact on collaboration practices, we conducted multiple regression analyses where group affiliation (SAMH vs. comparison group) predicted a range of characteristics of collaboration practices, from organizational practices (meeting frequency) to the quality of collaborative practice (i.e., reflection on process, reflection on roles). In Model 1, we conducted several regression analyses with group affiliation as the independent variable predicting the dependent variables. Gender, age, and living conditions were controlled in these analyses. In Model 2, we conducted the same analyses controlling for all variables simultaneously. Results from these analyses, as depicted in Table 2, showed that group membership predicted both the frequency of meetings and newly created professional practices. In other words, being in the SAMH group predicted less frequent meetings and more innovation compared to being in the comparison group.

To investigate factors that may be related to innovation in teams, we conducted hierarchical multiple regressions with innovation in teams as the dependent variable. In Step 1 , only background variables such as gender, age, and living conditions were entered as predictor variables. Analyses showed no relationship between these variables and innovation in collaboration (see Table 3 ). When entering frequency of meetings and experienced need for collaboration between disciplines into the model (Step 2), the total variance explained by the model increased to $6 \%$. Knowledge of other professions and openness and support in teams were additionally entered in Step 3, increasing explained variance to $13 \%$. However, only openness and experienced support showed unique, statistically significant contributions to the variance in team innovation. In Step 4, we entered reflection on process and reflection on roles into the model, and explained variance increased to $27 \%$. In this model, reflection on process and reflection on roles were unique, significant predictors of innovations in teams. 
Table 2 Linear regression models comparing the intervention (SAMH) group with the comparison group on collaboration outcomes

\begin{tabular}{|c|c|c|c|c|c|c|}
\hline \multirow[t]{2}{*}{ Dependent variables } & \multicolumn{3}{|l|}{ Model 1} & \multicolumn{3}{|l|}{ Model 2} \\
\hline & $B$ & Beta & $R^{2}$ & $B$ & Beta & $R^{2}$ \\
\hline Frequency of meetings & $-.46 * *$ & -.18 & .04 & $-.53^{* *}$ & -.21 & .09 \\
\hline Need for multidisciplinary teams & -.02 & -.01 & .02 & -.03 & -.02 & .09 \\
\hline Knowledge of other professions & .02 & .01 & .03 & -.01 & -.01 & .11 \\
\hline Openness and experienced support & .11 & .08 & .01 & .00 & .00 & .38 \\
\hline Reflection on process & .12 & .06 & .01 & -.12 & -.06 & .35 \\
\hline Reflection on roles & $.28^{*}$ & .16 & .03 & .15 & .09 & .51 \\
\hline Newly created professional practices & $.27 *$ & .15 & .03 & $.24 * *$ & .14 & .24 \\
\hline
\end{tabular}

Comparison group $=1, \mathrm{SAMH}$ group $=2$. Gender, age, and living conditions are controlled for in Model 1 . Other characteristics of collaboration practices are additionally controlled for in Model 2

${ }^{*} p<.05, * * p<.01, * * * p<.001$
Table 3 Hierarchical multiple regression model predicting innovation in teams

\begin{tabular}{lrrrc}
\hline & Step 1 & Step 2 & Step 3 & Step 4 \\
\hline Gender & -.04 & .01 & -.00 & .00 \\
Age & .09 & .09 & .09 & .05 \\
Living conditions & -.08 & -.03 & -.04 & -.08 \\
Frequency of meetings & & .10 & .07 & .10 \\
Need for multidisciplinary teams & & $.18^{*}$ & .11 & .10 \\
Knowledge of other professions & & & .02 & .07 \\
Openness and experienced support & & & $.28^{* * *}$ & .00 \\
Reflection on process & & & & $.27^{* * *}$ \\
Reflection on roles & & & & $.26^{* * *}$ \\
$R^{2}$ & .02 & .06 & .13 & .27 \\
$R^{2}$ change & .02 & .04 & .07 & .14 \\
\hline
\end{tabular}

Gender is coded $1=$ female, $2=$ male. Regression coefficients reported in the table are standardized

$* p<.05, * * p<.01, * * * p<.001$

\section{Discussion}

The main purpose of this article was to map the organization and quality of collaboration between disciplines in school and to determine whether the R\&D project SAMH affected collaboration practices. We found two main ways of organizing collaboration between disciplines, namely meetings organized by the municipality and meetings organized by schools. We did not find any significant differences in who participated in municipality meetings compared to school meetings.

Given the variation in collaboration organization, we expected that organization at different levels would have an effect on the quality of collaboration. However, the analyses did not find support for this expectation. The main reason for this finding is probably that variation in members, team agenda, and goals are not "standardized" in teams organized by schools and municipalities. In this sense, some part of the national education policy for enhancing local initiatives of collaboration may be justified by the non-significance of differences in organizational forms.

\section{SAMH Municipalities Showed More Innovation, but Fewer Meeting Points}

The main finding of the study was that SAMH was positively associated with newly created professional practices, or socalled innovative practices (Hammerness et al., 2005). The SAMH project was designed to promote collaboration, especially between teachers and health professionals, and as a preliminary conclusion, it seemed that the project improved the quality of collaboration. Drawing on the qualitative data from the SAMH project, we present and discuss our assumptions on the realities behind the comparatively high score on innovation practices for the schools participating in this project.

SAMH municipalities and schools were trained in developmental work, and school managers, school staff, and collaboration partners attended dialogue conferences where they discussed and operationalized how to work better to promote mental health locally. Different strategies were developed, and teachers and collaborating partners discussed challenges impeding collaboration. Such common challenges included teachers experiencing difficulties knowing when to seek help from other professionals, collaboration partners that wanted closer collaboration with school but did not experience openness from schools, and challenges with differences in confidentiality between teachers and health professionals.

Through qualitative methods such as observation and interviews, we noticed in the beginning of the project period variations in who participated in the collaboration team meetings and in the roles taken by professionals from different disciplines. Some schools had collaboration teams with one or two other disciplines attending, in which these disciplines embodied a role as advisors or experts. In such 
collaboration teams, teachers presented challenging "cases," and advice on what to do was given by the "experts" from other disciplines. A common challenge in such teams was that the experts to a large extent provided solutions from an individualistic approach, whereas teachers to a larger extent needed perspectives and solutions suitable in a classroom setting. As a result, teachers often reported difficulties addressing individual needs of students, while at the same time teaching and managing the whole class. In contrast, in less hierarchically organized teams, decision making was to a greater degree reported as a joint effort where teachers' perspectives were taken into account.

SAMH participants scored higher on innovation than participants in the comparison group. We interpret these high scores as an indicator of increasing interdisciplinary collaboration, from a more "hierarchical" mode of collaboration toward a mode, were different professions collaborated to a larger degree an equal footing. In effect, this change may reduce the tendency toward compartmentalization and increasing the tendency toward integrated efforts in collaboration on student-oriented tasks.

SAMH respondents reported fewer meetings per school year than the comparison group. This finding may indicate that collaborators in SAMH may have more effective meetings. Another interpretation is that collaboration also occurs more informally and continually, thereby reducing the need to meet with the full collaboration team. This interpretation was supported by our empirical material and by observations at dialogue conferences and interviews with leaders and teachers. Participants frequently reported that in schools where internal and external professionals had developed collaboration that was task-oriented rather than discipline- or role-oriented, collaboration on student-oriented tasks was often established through direct contact and not through formal fora.

One of the main intentions of implementing SAMH in schools was improving how professionals from different disciplines worked together and to find new ways of dealing with common challenges. This intention was put into work by offering and implementing a set of methods for participative development work in the schools and municipalities. There are reasons to believe that the form of developmental work applied in SAMH did affect the quality of collaboration between disciplines.

\section{Reflection on Roles and Process}

We expected to find differences in factors such as knowledge of other professions, reflection on process, and openness and support in team collaboration. Participants in SAMH reported somewhat higher mean scores on these variables, but the differences were not found to be significant between the SAMH and comparison groups. The reason could be that professionals in Norway, for the most part, have internalized the importance of working with other disciplines as a means of fulfilling their mandates and providing children with a holistic and coordinated service. As a result, teachers and health professionals in Norway may in general be open to collaborations and report sufficient knowledge of other professions in collaboration settings. However, openness and sufficient knowledge may not necessarily increase the quality of collaboration by itself. Both the SAHM project and other research on teamwork in schools emphasize the crucial role of frequent, continuous, and concrete discussions about practice for effective practice in educational settings (Borg, Christensen, Fossestøl, \& Pålshaugen, 2015; Borg et al., 2014).

We expected to find more reflection practices in the SAMH municipalities than the comparison group, given that we arranged dialogue conferences to increase reflection practices among actors working to promote mental health in schools. SAMH municipalities did indeed report significantly higher mean scores on reflection on roles than did the comparison group, such as team members discussing similarities and differences in the way they work and being flexible when discussing which members should be involved in interventions. It could be argued that reflection on roles is easier to achieve than reflection on process. Reflection on roles may lead to increased knowledge about each other and more flexibility in how collaborators work together.

Results for both the SAMH and comparison groups showed that reflection on process received the lowest scores of the four collaboration quality variables, thereby indicating that this activity was less likely to occur in collaboration settings compared to the other three. Reflection on process is, as such, thought to be a more time-consuming and "difficult" task to fit into a busy professional schedule. Observations indicated that collaboration teams prioritized discussions concerning concrete challenges in the school or community rather than reflecting on practices. However, taking the time to discuss and evaluate team collaboration is important for high-quality solutions and sustainable changes.

\section{Limitations}

There are some limitations in this project that are important to consider when interpreting the results. First, we used a cross-sectional survey that was conducted at the end of 4 -year project on the implementation of SAMH in four municipalities. We can therefore not be fully certain that the difference between the SAMH and comparison groups did not occur by chance. However, we compared the two samples on different background variables and found no differences between the groups, indicating that the two groups are comparable. 
Second, it is important to note that the results are based on respondents' subjective assessments, and the connection to what actually occurs in collaboration teams is not known. This issue is, of course, a common challenge for all research using questionnaires to study the quality of interdisciplinary collaboration. We believe that the use of supplementary qualitative data from the $\mathrm{SAMH}$ project in the interpretation of the results from the survey is valuable in dealing with this challenge.

Third, while our study findings provide valuable information about interdisciplinary collaboration in teams, they do not address how collaboration between teachers and healthcare professionals outside of such teams could be improved. Future research may address such issues by focusing on more general aspects of collaboration between the educational sector and mental health service providers.

\section{Conclusion}

Collaboration between different disciplines in school is supposed to be a means to provide children with a holistic and coordinated service securing good mental health and learning. In this study, we sought to map the quality of interdisciplinary collaboration practices in Norway and study the effect of an R\&D project implemented in four municipalities.

The study showed variability in the organization of collaboration teams, such as who the organizers were and who participated in team collaboration. The organization did not affect collaboration practices. However, discussing the roles and responsibilities and reflecting on process were likely to produce innovations for the team.

The major finding of the study was that the municipalities that had implemented SAMH reported more innovation practices in collaboration compared to others. We argue that the design of the project, where school management, school staff, and collaboration partners are prompted to discuss, decide, and evaluate collaborative efforts to promote student mental health in schools, is key factor for new practices to occur.

The current study's findings have important implications for collaboration work between disciplines by highlighting that the organizational aspects of multidisciplinary collaboration are less important than how collaboration is co-created by collaborators as actors.

Funding The SAMH project was funded by the Norwegian Directorate for Education and Training and the Directorate of Health.

\section{Compliance with Ethical Standards}

Conflict of interest The authors declare that they have no conflict of interests.
Ethical Approval All procedures performed in studies involving human participants were in accordance with the ethical standards of the institutional and/or national research committee and with the 1964 Helsinki Declaration and its later amendments or comparable ethical standards. This article does not contain any studies with animals performed by any of the authors.

Informed Consent Informed consent was obtained from all individual participants included in the study.

Open Access This article is distributed under the terms of the Creative Commons Attribution 4.0 International License (http://creativeco mmons.org/licenses/by/4.0/), which permits unrestricted use, distribution, and reproduction in any medium, provided you give appropriate credit to the original author(s) and the source, provide a link to the Creative Commons license, and indicate if changes were made.

\section{References}

Anderson-Butcher, D., Ashton, D. (2004). Innovative models of collaboration to serve children, youths, families, and communities. Children \& Schools, 26(1), 39-53.

Anderson-Butcher, D., Lawson, H. A., Bean, J., Flaspohler, P., Boone, B., \& Kwiatkowski, A. (2008). Community collaboration to improve schools: Introducing a new model from Ohio. Children and Schools. https://doi.org/10.1093/cs/30.3.161.

Austin, J. E. (2000). The collaboration challenge: How nonprofits and business succeed through strategic alliances. San Francisco: Jossey-Bass.

Banks, T., Squires, G., \& Anhalt, K. (2014). Interdisciplinary collaboration: Cognitive behavioral interventions in special education and school psychology. Creative Education. https://doi.org/10.4236/ ce.2014.510089.

Blossing, U., Nyen, T., Söderström, Å., \& Tønder, A. H. (2012). Utvikling av skoler. Prosesser, roller og forbedringshistorier [Developing schools. Processes, roles and stories of change]. Oslo: Gyldendal Akademiske.

Borg, E., Christensen, H., Fossestøl, K., \& Pålshaugen, Ø. (2015). Hva larerne ikke kan! Et kunnskapsgrunnlag for satsning på bruk av flerfaglig kompetanse i skolen [A knowledge base for better use of inter-disciplinary competence in school]. Report No. 6, Oslo: Work Research Institute.

Borg, E., Drange, I., Fossestøl, K., \& Jarning, H. (2014). Et lag rundt lareren. En kunnskapsoversikt [A support network for teachers. A review of the literature on inter-disciplinary collaboration for learning]. Report No. 8, Oslo: Work Research Institute.

Bronstein, L. R. (2003). A model for interdisciplinary collaboration. Social Work, 48(3), 297-306.

Bronstein, L., \& Abramson, J. S. (2003). Understanding socialization of teachers and social workers: Groundwork for collaboration in the schools. Families in Society, 84(3), 1-8.

Bru, E., Cosmovici Idsøe, E., \& Øverland, K. (Eds.). (2016). Psykisk helse i skolen [Mental health and school]. Oslo: Universitetsforlaget.

Choi, B. C. K., \& Pak, A. W. P. (2006). Multidisciplinarity, interdisciplinarity, and transdisciplinarity in health research, services, education, and policy: 1 . Definitions, objectives, and evidence of effectiveness. Clinical and Investigative Medicine, 29(6), 351-364.

Choi, B. C. K., \& Pak, A. W. P. (2007). Multidisciplinarity, interdisciplinarity, and transdisciplinarity in health research, services, education and policy: 2. Promotors, barriers, and strategies 
of enhancement. Clinical and Investigative Medicine, 30(6), E224-E232.

Connolly, M., \& James, C. (2006). Collaboration for school improvement: A resource dependency and institutional framework of analysis. Educational Management Administration and Leadership. https://doi.org/10.1177/1741143206059540.

Decuyper, S., Dochy, F., \& Van den Bossche, P. (2010). Grasping the dynamic complexity of team learning: An integrative model for effective team learning in organisations. Educational Research Review. https://doi.org/10.1016/j.edurev.2010.02.002.

Ekornes, S. (2015). Teacher perspectives on their role and the challenges of inter-professional collaboration in mental health promotion. School Mental Health. https://doi.org/10.1007/s1231 0-015-9147-y.

Ekornes, S., Hauge, T. E., \& Lund, I. (2012). Teachers as mental health promoters: A study of teachers' understanding of the concept of mental health. International Journal of Mental Health Promotion. https://doi.org/10.1080/14623730.2013.798534.

Eriksen, I. M., \& Lyng, S. T. (2015). Skolers arbeid med elevenes psykososiale milj $\phi$. Gode strategier, harde nфtter og blinde flekker [Schools' work with the students' psycho-social environment. Good strategies, hard nuts and blind spots]. Report no. 14, Oslo: Norwegian Social Research.

Funnell, S. C., \& Rogers, J. R. (2011). Purposeful program theory: Effective use of theories of change and logic models. San Francisco: Jossey-Bass.

Gajda, R., \& Koliba, C. (2007). Evaluating the imperative of intraorganizational collaboration: A school improvement perspective. American Journal of Evaluation. https://doi.org/10.1177/10982 14006296198.

Galvin, K., \& Erdal, B. (2013). Tverrfaglig samarbeid i praksis: Til beste for barn og unge i kommune-Norge [Interprofessional Collaboration in Practice]. Oslo: Kommuneforlaget.

Gustavsen, B. (1992). Dialogue and development. Assen: Van Gorcum.

Hammerness, K., Darling-Hammond, L., Brasford, J., Berliner, D., Cochran-Smith, M., McDonald, M., et al. (2005). How teachers learn and develop. In L. Darling-Hammond \& J. Brasford (Eds.), Preparing teachers for a changing world (pp. 358-389). San Francisco: Jossey-Bass.

Hart, A. W. (1998). Marshaling forces: Collaboration across educator roles. In D. G. Pounder (Ed.), Restructuring schools for collaboration: Promises and pitfalls (pp. 79-106). New York: State University of New York Press.

Holen, S., \& Waagene, E. (2014). Psykisk helse i skolen. Utdanningsdirektoratets spфrreunders $\phi$ kelse blant larere, skoleledere og skoleeiere [Mental health in school. A survey by The Norwegian Directorate for Education and Training among teachers and school leaders]. Report No. 9, Oslo: NIFU.

Hornby, G., \& Atkinson, M. (2003). A framework for promoting mental health in school. Pastoral Care in Education. https://doi. org/10.1111/1468-0122.00256.

Hustad, B.-C., Strøm, T., \& Strømsvik, C. L. (2013). Kompetanse i PPtjenesten-til de nye forventingene? Kartlegging av kompetansen i PP-tjenesten [Competence in educational psychology services - new expectations?]. NF-report No. 2, Bodø: Nordland Research Institute.

Johnson, S. R., Pas, E. T., Loh, D., Debnam, K. J., \& Bradshaw, C. P. (2017). High school teachers' openness to adopting new practices: The role of personal resources and organizational climate. School Mental Health. https://doi.org/10.1007/s12310-016-9201-4.

Little, J. W. (1987). Teachers as colleagues. In V. Richardson-Koehler (Ed.), Educators' handbook. White Plans: Longman.

Løken, M. (2017). School as an arena for pupils' mental wellbeing: A Norwegian study on systematic development work. In O'Neill, H. (Ed.), Wellbeing in our schools: International perspectives.
CIDREE Yearbook 2017. Dublin: National Council for Curriculum and Assessment.

Mattessich, P. W., \& Monsey, B. R. (1992). Collaboration: What makes it work?. St. Paul: Amherst H. Wilder Foundation.

Maynard, B. R., Kjellstrand, E. K., \& Thompson, A. M. (2013). Effects of check and connect on attendance, behavior, and academics: A randomized effectiveness trial. Research on Social Work Practice. https://doi.org/10.1177/1049731513497804.

Mebane, D., \& Galassi, J. (2003). Variables affecting collaborative research and learning in a professional development school partnership. The Journal of Educational Research, 96(5), 259-268.

Meirink, J. A., Imants, J., Meijer, P. C., \& Verloop, N. (2010). Teacher learning and collaboration in innovative teams. Cambridge Journal of Education. https://doi.org/10.1080/0305764x.2010.481256.

Mellin, E. A. (2009). Unpacking interdisciplinary collaboration in expanded school mental health: A conceptual model for developing the evidence base. Advances in School Mental Health Promotion. https://doi.org/10.1080/1754730X.2009.9715706.

Mellin, E. A., Bronstein, L., Anderson-Butcher, D., Amorose, A. J., Ball, A., Green, J. (2010). Measuring interprofessional team collaboration in expanded school mental health: Model refinement and scale development. Journal of Interprofessional Care, 24(5), 514-523.

Mellin, E. A., Anderson-Butcher, D., \& Bronstein, L. (2011). Strengthening interprofessional team collaboration: Potential roles for school mental health professionals. Advances in School Mental Health Promotion. https://doi.org/10.1080/1754730X.2011.97156 29.

Ødegård, A. (2005). Perceptions of interprofessional collaboration in relation to children with mental health problems: A pilot study. Journal of Interprofessional Care. https://doi.org/10.1080/13561 820500148437.

Pålshaugen, Ø. (2014). Action research for democracy—A Scandinavian approach. International Journal of Action Research, 10(1), 98-115.

Porter, G., Epp, L., \& Bryan, S. (2000). Collaboration among school mental health professionals: A necessity, not a luxury. Professional School Counseling, 3(5), 315.

Pounder, D. G. (1998). Promises and pitfalls of collaboration: Synthesizing dilemmas. In D. G. Pounder (Ed.), Restructuring schools for collaboration: Promises and pitfalls (pp. 163-168). New York: State University of New York Press.

Schmoker, M. (2005). No turning back: The Ironiclad case for professional learning communities. In R. Dufour, R. Eaker, \& R. DuFour (Eds.), On common ground: The power of professional learning communities (pp. 135-153). Bloomington: National Education Services.

Shoffner, M. F., \& Briggs, M. K. (2001). An interactive approach for developing interprofessional collaboration: Preparing school counselors. Counselor Education and Supervision. https://doi. org/10.1002/j.1556-6978.2001.tb01252.x.

Suren, P., Furu, K., Reneflot, A., Nes, R. B., Torgersen, L., \& Bakken, I. J. (2016). Mental disorders among children and adolescents in Norway. Oslo: Norwegian Institute of Public Health.

Suren, P., Furu, K., Reneflot, A., Nes, R. B., Torgersen, L., \& Bakken, I. J. (2018). Quality of life and mental disorders among children and adolescents. Oslo: Norwegian Institute of Public Health.

Uthus, M. (2017). Elevenes psykiske helse i skolen. Utdanning til å mestre egne liv [Students' mental health in school. Education to manage life]. Oslo: Gyldendal.

Vangrieken, K., Dochy, F., Raes, E., \& Kyndt, E. (2015). Teacher collaboration: A systematic review. Educational Research Review. https://doi.org/10.1016/j.edurev.2015.04.002.

Weist, M. D., Mellin, E. A., Chambers, K. L., Lever, N. A., Haber, D., \& Blaber, C. (2012). Challenges to collaboration in school 
mental health and strategies for overcoming them. Journal of School Health. https://doi.org/10.1111/j.1746-1561.2011.00672.x.

Welch, M., Sheridan, S. M., Fuhriman, A., Hart, A. W., Connell, M. L., \& Stoddart, T. (1992). Preparing professionals for educational partnerships: An interdisciplinary approach. Journal of Educational and Psychological Consultation, 3(1), 1-23.

White Paper No. 19. (2009-2010). Norwegian Ministry of Education. Tid for laring. Oppfølging av tidsbruksundersøkelsen [Time for learning. Follow-up of the time-use study]. Oslo: Ministry of Education and Research.

White Paper No. 21. (2016-2017). Early intervention and quality in school. Oslo: Ministry of Education and Research.
WHO. (2004). Promoting mental health: Concepts, emerging evidence, practice. Geneva: World Health Organization.

Wichstrøm, L., Berg-Nielsen, T. S., Angold, A., Egger, H. L., Solheim, E., \& Sveen, T. H. (2012). Prevalence of psychiatric disorders in preschoolers. Journal of Child Psychology and Psychiatry, 53, 695-705. https://doi.org/10.1111/j.1469-7610.2011.02514.x.

Willumsen, E., \& Ødegård, A. (2016). Tverrprofesjonelt samarbeidEt samfunnsoppdrag [Interdisciplinary collaboration] (2nd ed.). Oslo: Universitetsforlaget.

Winitzky, N., Sheridan, S. M., Crow, N., Welch, M., \& Kennedy, C. (1995). Interdisciplinary collaboration: Variations on a theme. Journal of Teacher Education, 46(2), 109-119. 